\title{
Euclides da Cunha e a Escola Politécnica de São Paulo
}

\author{
JOSÉ CARLOS BARRETO DE SANTANA
}

unIR EuClides Da CUNHA e a Escola Politécnica de São Paulo está o so-
nho daquele, longamente acalentado e não realizado, de um dia inte-
grar o quadro de professores da Escola.

Esta pouco estudada pretensão do engenheiro e bacharel em Matemática, Ciências Físicas e Naturais pode ser melhor entendida se a situarmos no contexto de sua vida nômade e o contraponto da busca de uma atividade fixa, que pudesse assegurar uma razoável estabilidade econômica e tranqüilidade para o desenvolvimento de suas inquietações intelectuais.

Elza Nadai (1981:67) localiza ainda no Império a manifestação do desejo paulista no sentido de se criar uma escola de engenharia na então província de São Paulo. Apoiada na existência de significativa rede ferroviária e diversas oficinas de manutenção, a Lei Provincial $n^{\circ} 10$, de 24 de maio de 1835 , criou o Gabinete Topográfico, uma escola de engenheiros construtores de estradas que não chegou a ser instalado.

O advento da República, ao passo em que possibilitou relativa descentralização política e maior autonomia dos governos estaduais, encontrou a economia paulista agrária-exportadora baseada na cafeicultura, a qual desde as duas décadas anteriores vinha crescendo na cena nacional, ampliando seu peso econômico e político, e deflagrando processos de industrialização e urbanização que implicavam a necessidade de criação e melhoria dos serviços públicos, a instalação e ampliação de ferrovias e o escoamento dos produtos no mercado internacional, preparando-se para o exercício de novas funções advindas com o desenvolvimento econômico e a conseqüente urbanização. Nesse contexto não é dificil compreender porque a Escola Politécnica de São Paulo foi a primeira instituição de ensino superior criada pelo governo de São Paulo após a República, considerada a instituição modelar de ensino superior durante a Primeira República (Nadai, 1981:64).

Fundada em 1893, a Escola Politécnica tem sua origem relacionada à determinação do Congresso Legislativo do Estado de São Paulo de criar uma escola de engenharia. A Lei ${ }^{\circ} 191$ de 24 de agosto de 1893 aprovou o Regulamento da Escola Politécnica de São Paulo. 
Enquanto as escolas Politécnica do Rio de Janeiro e de Minas de Ouro Preto adotaram modelos franceses para os seus cursos (Figueirôa, 1992:11), a Escola Politécnica de São Paulo optou pelo modelo suíço das Tecnische Hochschule. Segundo Vargas (1993:A-2), essa opção resultou num ensino prático baseado em ciências aplicadas às artes $\mathrm{e}$ às indústrias, sem priorizar nenhum, diferindo da idéia positivista de ensino eminentemente matemático, de cujos princípios seriam deduzidas as aplicações práticas.

O governo paulista encontrou no fundador e primeiro diretor da Escola, Antonio Francisco de Paula Souza (1843-1917), um colaborador precioso para implantar o projeto da Politécnica. Paula Souza dirigiu a Escola Politécnica por um quarto de século, imprimindo-lhe a sua marca a ponto de seus contemporâneos afirmarem que sem ele, provavelmente, a evolução não teria sido a mesma (Nadai, 1981:98).

O engenheiro Paula Souza nasceu em Itu-SP, descendente de família de grande influência política e econômica, buscando nos Estados Unidos e na Europa, onde permaneceu por longos anos, os elementos da sua formação profissional na área de engenharia. Freqüentou a Eidgenossische Technische Holbschule de Zurich entre 1861 e 1863 (Santos, 1985:47) e formou-se na Technische Holbschule de Carlsruch, também na Suíça, em 1865 (Vargas, 1993:A-2). A formação de Paula Souza explica a adoção do modelo suíço pela Escola Politécnica de São Paulo.

Em 1885, Euclides da Cunha (1866-1909) prestou exame de matemática e desenho na Escola Politécnica-RJ, na qual cursou apenas um ano, aparentemente por falta de condições econômicas. No ano seguinte assentou praça na Escola Militar da Praia Vermelha-RJ. A passagem de Euclides da Cunha pela Escola Militar seria desapercebida, não fossem as marcas indeléveis de uma formação cientificista e do episódio de sua insubordinação durante visita do ministro da Guerra à Escola.

Era o ano de 1888 e o cadete Euclides da Cunha, defensor de idéias republicanas, recusando a continência ao representante da monarquia “(...) atirou $o$ sabre ao chão, proferindo palavras que reforçavam o gesto de desacato sensacional, deixando estupefactos os próprios companheiros de armas que, à hora, não tiveram coragem de cumprir o combinado, em beneficio da propaganda republicana" (Andrade, 1960:33). Expulso do Exército, Euclides a ele retornou após a proclamação da República e, por licença de Deodoro da Fonseca, voltou a cursar a Escola Militar, completando os seus estudos em 1891.

Euclides da Cunha permaneceu como oficial-engenheiro até o ano de 1896 quando deixa definitivamente a farda, reformado no posto de tenente. Foi a sua opção pela atividade de engenheiro civil, cuja função, sob licença do Exército, já 
exercia desde 1895 na Superintendência de Obras Públicas do Estado de São Paulo.

A engenharia civil foi para Euclides a carreira fatigante, a engenharia precipitada que o levaria a peregrinar pelo interior de São Paulo. Era da engenharia que Euclides da Cunha tirava o sustento de sua família, o que durante toda a sua vida foi motivo de preocupações.

Ainda nos idos de 1888, Euclides da Cunha iniciou um processo de colaboração com o jornal $A$ Provincia de S. Paulo, que teria prosseguimento após a República e a mudança do nome do periódico para $O$ Estado de S. Paulo.

Em 1892, o recém-graduado engenheiro Euclides da Cunha escreveu dois artigos para $O$ Estado de $S$. Paulo combatendo “(...) energicamente a maneira como foi organizada a Escola" (Cunha, 1896).

No primeiro dos artigos, datado de 24 de maio de 1892 , com o título "Instituto Politécnico", Euclides, tencionando definir o seu "modo de pensar acerca do projeto, apresentado pelo Sr. Paula Souza (...)", critica o “(...) desastroso projeto, apresentado agora ao Congresso do Estado, e que é entretanto amparado por um nome respeitável por muitos títulos" (Cunha, 1959:155).

Apontando "incorreções imperdoáveis" no projeto apresentado pelo engenheiro Antonio Francisco de Paula Souza, o crítico analisou a proposta do curso preparatório a partir de um enfoque positivista, com ênfase no que considerou uma quebra de hierarquia na "classificação científica", inadequação de termos para as matérias, ausência de ciências indispensáveis e a ausência de curso especial de engenharia geográfica.

O articulista considerou o projeto "vazio de orientação, incorretíssimo na forma, e filosoficamente deficiente, [repelindo] de todo a idéia de que ele [pudesse] vir a modelar nossa mentalidade futura" (Cunha, 1959:154-157).

A fixação de um prazo de três anos em que as matérias deveriam “(...) ser estudadas segundo programas organizados pelo futuro diretor da Escola" preocupava Euclides da Cunha por ver nesta uma medida na qual o "legislador abdica, assim, num terceiro, que pode ser incompetente. De sorte que a organização do projeto pertencerá afinal a este e não ao poder legislativo que a devia formular" (Cunha, 1959:157).

Não tendo sido contestado, Euclides volta a tratar do assunto no dia $1^{\circ}$ de junho de 1892, reafirmando as suas críticas e declarando que "apontando os defeitos e incorreções, muitos dos quais gravíssimos, de que está eivado o projeto (...) cumprimos um dever rudimentar - combater o erro" (Cunha, 1959:158).

A ausência de contestação levou o autor do artigo a declarar-se vencedor 
de uma polêmica que não aflorou, baseado no seu próprio entendimento de que “(...) ninguém ousaria arrostar as consequiências de negar os defeitos (...)" que ele apresentara: "nem mesmo o autor do projeto" (Cunha, 1959:158).

Intentando uma "missão reconstrutora" este segundo artigo procura demonstrar que a sociedade brasileira "(...) não comporta esse grande ideal de um preparo filosófico comum, presidindo a todas as atividades", conforme previa a proposta do curso preparatório do Instituto Politécnico, prescrevendo uma educação superior diferenciada de acordo com as cadeiras a serem criadas (Cunha, 1959:159).

As críticas de Euclides da Cunha ao projeto que antecedeu a criação da Escola Politécnica não o impediram de acalentar o desejo de nela ingressar como professor. Em agosto de 1893 Euclides encontrava-se à disposição do Ministério da Viação para praticar na Estrada de Ferro Central do Brasil e escreveu ao amigo Teodoro Sampaio, dando-lhe notícias pessoais, tratando de negócio pendente entre ambos e pedindo informações sobre a Escola Politécnica.

Muito embora não seja do meu conhecimento a atual existência das cartas de Euclides, o seu teor pode ser claramente deduzido a partir das respostas contidas em carta a ele endereçada por Teodoro Sampaio, datada de 19 de agosto de 1893: "Quanto a Escola Politécnica de São Paulo tenho a dizer-lhe que está votada verba no orçamento para a sua instalação e funcionamento dos dois primeiros anos dos cursos de Engenharia Civil, e curso de Artes Mecânicas. As cadeiras serão preenchidas por nomeação, e só mais tarde, as restantes o serão por concurso. Consta-me que o governo daqui esta nimiamente escrupuloso na escolha do pessoal docente e pessoal diretor, o que muito louvo, mas nada de positivo consta em que ele se tenha comprometido para com este ou aquele. Creio que neste assunto não reinará e não 'prevalecerá' a política o que já não é pouca coisa. O Dr. Cesário Motta está animado dos melhores desejos de bem dotar o seu Estado com escolas superiores e escolas de instrução primária: é esse um assunto de suas cogitações diárias" (Sampaio, 1893).

Ainda do ano de 1893, uma carta do advogado paulista Reinaldo Porchat para Euclides da Cunha traz informações sobre a permanência do interesse deste pela Escola Politécnica. Em correspondência de 26 de novembro, Porchat lamentou o fato de o governo de São Paulo não ter aceito Euclides para "[abrilhantar] com o pujante talento uma cadeira de lente da Escola Politécnica de São Paulo".

Criticando o que considerava uma "censurável preterição", o advogado paulista afirmava que: "(...) afeito como estou a ver sempre desprezados aqueles que não sabem babar bajulações às plantas dos poderes públicos, em nada me admira mais esse deplorável erro dó Bernardino [de Campos, governador de 
São Paulo]. / Se o atributo indispensável era o renome científico para um lugar de professor, não sei com que direito te deixaram de lado, para nomear uns cientistas desconhecidos no mundo teórico, como Anhaia, Garcia Redondo e Ramos de Azevedo. / Se acerto houve com as nomeações de Gonzaga de Campos e Teodoro Sampaio (1), também houve grande violência não se aproveitando os teus meritórios serviços científicos" (Porchat, 1893).

Parece-me evidente que Reinaldo Porchat não se dirigiria nestes termos ao amigo se não tivesse conhecimento das pretensões e, até mesmo, de uma possível movimentação de bastidores visando ao aproveitamento de Euclides da Cunha para a composição do quadro de professores da Escola Politécnica de São Paulo. A crítica do advogado paulista deixa claro o seu entendimento de que prevaleceu o critério político na escolha dos primeiros lentes da Escola, ao contrário da crença de Teodoro Sampaio.

Além disto, Porchat devia estar informado do ânimo de Euclides da $\mathrm{Cu}$ nha em persistir na tentativa de se tornar lente da Escola recém-criada, pois conclui o assunto de forma esclarecedora: "Cônscio do teu valor, estás, porém, disposto a entrares nessa escola pela porta livre do concurso. Bato-te palmas por isso" (Porchat, 1893).

Antes que surgisse a oportunidade de um concurso para professor da Politécnica, o tenente-engenheiro Euclides da Cunha foi transferido - por determinação de Floriano Peixoto - em 28 de março de 1894, da capital do país para a cidade de Campanha-MG.

No período entre 1895 e 1896, em São Paulo, Euclides da Cunha consolidou a sua opção pela engenharia civil enquanto atividade profissional, mas ainda era um “(...) homem titubeante, preocupado em arrumar alguma ocupação relativamente sólida e estável para a vida (...)" (Andrade, 1960:77).

Para melhor exercer a profissão de engenheiro civil fez convergir as suas atenções “(...) para os livros práticos, deixando provisoriamente de lado os filósofos, o Comte, o Spencer, o Huxley etc.” dedicando-se às “(...) páginas ásperas dos Aide-Memoires ou dos Enginer's pocketbooks (...)” (Cunha, 1966:606).

Em meio à busca de uma atividade estável, trabalhando em caráter precário, Euclides da Cunha revela a João Luís (um dos amigos de Campanha), as suas preocupações quanto ao futuro e a crença na realização do seu “(...) grande sonho, a única aspiração constante que de há muito tenho: tirar, por concurso, uma cadeira na Escola de Engenharia daqui. 'Logo que abrirem as inscrições avisar-te-ei - e fique já certo de que não dispensarei, absolutamente não dispensarei, a tua presença no dia em que tiver de defender a tese que apresentar, dizerte isto é dizer-te que tenho estudado alguma coisa" (Cunha, 1966:604-605). 
Nesta carta a João Luís, ou em qualquer outro documento consultado, não informa Euclides sobre a cadeira à qual aspira o acesso através do concurso, nem qual o assunto estudado. A pista para desvendar a questão encontra-se em outra carta ao mesmo amigo, datada de 23 de abril de 1896, quando se diz "absorvido pelo estudo da Mineralogia, vivendo numa áspera sociedade de pedras (...)" (Cunha, 1896).

Das cadeiras existentes na Escola Politécnica a que melhor se ajustava ao estudo que absorvia Euclides da Cunha era a de Mineralogia e Geologia. Jazidas de adubos químicos no Brasil (Anuário da Escola Politécnica, 1900:88-96), que pelo seu próprio título e programa mostrava a imperiosa necessidade de que fossem aprofundados os conhecimentos em mineralogia de um pretendente a um concurso com esta finalidade.

As inscrições para o concurso foram abertas, mas na correspondência de 23 de abril, citada anteriormente, já informava Euclides do seu estado de espírito: "Comecei, com todo o afinco a estudar para um próximo concurso (ao qual ainda não renunciei); no fim quase, de um mês, porém começou a dar-se o seguinte: o cidadão $\mathrm{A}$, cheio de íntima convicção, baseado em anteriores exemplos, fatos passados com outros, afirmava-me que isto de concurso em S. Paulo não valia nada, sendo invariavelmente nomeado persona grata do governo, citando-se mesmo o fato recente da anulação de um concurso pelo fato de ter má colocação cidadão favorecido pelo apoio oficial. Logo após o cidadão $\mathrm{B}$, confidencialmente, fazia alusão à minha seita positivista (eu, positivista!) e à birra especial de algumas influências pelos que a professam. / O cidadão $C$, lembravame antigos artigos meus, de 92, no Estado, em que combati energicamente a maneira pela qual foi organizada a Escola etc. Um outro, comunica-me a existência de terrível adversário, um dos primeiros geólogos do Brasil, discípulo e braço direito de Gorceix etc. etc. / Imagina que imenso esforço para ficar a cavaleiro de tudo isto..."

Cabe aqui a análise dos pontos levantados pelos cidadãos para entender qual a amplitude deles sobre o ânimo de Euclides da Cunha.

A afirmação do "cidadão A", sobre a nomeação de persona grata do governo é seguida com a exemplificação da anulação de um concurso devido à má colocação de um "candidato oficial".

Esta prática não era incomum e o próprio Euclides viria a ser beneficiado pelo poder de escolha do governo federal quando do concurso para professor do Colégio D. Pedro II em 1909. Após obter o $2^{\circ}$ lugar no concurso para a cadeira de Lógica, a interferência do Barão do Rio Branco garantiu para Euclides da Cunha a nomeação, sendo preterido o candidato Faria Brito, classificado em $1^{\circ}$ lugar. 
O possível candidato a lente não tinha conhecimento de que no seio da Congregação da Politécnica predominavam largamente as opiniões favoráveis à supressão do concurso que, segundo o Diretor Paula Souza, “(...) só males pode trazer à instituição e à boa marcha dos trabalhos (...) [pois] não tem as virtudes que se lhe atribui de fazer a seleção do professorado, e, bem pelo contrário, contribuirá para afastar da Escola os homens realmente competentes" (Atas da Congregação, 1896).

Boa parte da $7^{\text {a }}$ sessão ordinária da Congregação, em 2 de setembro de 1896, foi destinada à discussão para se encontrar uma solução que permitisse a apresentação ao Congresso Estadual de um projeto de supressão dos concursos sem que o ônus da medida fosse atribuído pela opinião pública à Escola.

Enquanto tais objetivos não foram alcançados permaneceram os procedimentos legais de inscrição para os mesmos, conforme fica claro das reuniões seguintes, até a entrada em vigor de uma “(...) nova lei autorizando o governo a fazer nomeações para preenchimento das vagas existentes no corpo docente independente dos concursos (...)", diante da qual o Diretor comunica à Congregação, em 18 de janeiro de 1897, a "(...) suspensão dos editais para concursos cujas inscrições ainda se acham abertas" (Atas da Congregação, 1897).

O outro cidadão que comunicou "a existência de um terrível adversário, um dos primeiros geólogos do Brasil, discípulo e braço direito de Gorceix (...)" certamente estava se referindo ao mesmo Dr. Oliveira, que o diretor da Politécnica considerava "(...) pessoa que preencheria com toda proficiência a cadeira de mineralogia e geologia" (Atas da Congregação, 1896).

Tratava-se de Francisco de Paula Oliveira, aluno de geologia e mineralogia do professor Claude-Henri Gorceix na Escola de Minas de Ouro Preto e que trabalhou como geólogo na primeira equipe da Comissão Geográfica e Geológica de São Paulo.

O diretor Paula Souza tinha em Francisco Oliveira “(...) a pessoa cujo nome desejava apresentar para assumir a regência interina da cadeira de Mineralogia e Geologia [mas que] declarou não poder aceitar a incumbência, o que é de lastimar, vista a sua capacidade técnica (...)" (Atas da Congregaf̧ão, 1896). Dr. Oliveira teria se recusado a participar do concurso pelo fato de nele constar elementos de todas as matérias da $2^{\mathrm{a}}$ seção.

Quanto à alusão feita pelo "cidadão B" à "seita positivista" e à "birra especial de algumas influências" pelos que a professam, independentemente da nãoaceitação pacífica de Euclides da Cunha da pecha que lhe era atribuída, pode-se argumentar que a existência de uma "birra especial" não significava impossibilidade de acesso de positivistas à Escola. 
Nadai (1981:116) identificou a existência de uma polêmica interna à Politécnica, entre positivistas e não-positivistas, em torno de questões relacionadas com o ensino da ciência pura. Apesar de a autora considerar que a divergência dos grupos constituiu um obstáculo à penetração do positivismo na Escola, $o$ fato é que quando, a partir de 1900, foi travada a controvérsia entre a Politécnica e a Comissão Geográfica e Geológica a respeito do mapeamento do estado de São Paulo, o grupo positivista, liderado por Francisco Bhering, mostrou-se forte o suficiente para obter da Congregação um voto unânime de louvor, em polêmica que perdurou por quase três anos e deteriorou a amizade entre Paula Souza e o geólogo Orville Derby, diretor da Comissão Geográfica e Geológica da São Paulo (Figueirôa, 1987:84-90).

O próprio Euclides da Cunha não se considerava essencialmente um positivista e Olímpio de Souza Andrade o viu "integrando o grupo dos spencerianos da Escola Militar, ao contrário da maioria dos alunos, partidários da ortodoxia comtista (...)" (Andrade, 1960:31). A preferência de Euclides pelo spencerismo estava bem ao gosto do cientificismo que pairava no Brasil do último quartel do século passado.

Assim, embora os artigos citados pelo "cidadão C", e já aqui tratados, estejam fundamentados num enfoque positivista, acredito que, para além do conteúdo filosófico das críticas, pesava fundo entre "algumas influências" da Escola a forma desassombrada e contundente da crítica de um jovem engenheiro, que não hesitava em associar nomes aos supostos defeitos do projeto.

Em 28 de abril de 1896, volta Euclides da Cunha a tratar do concurso em carta a outro amigo de Campanha-MG, Dr. Brandão, a quem revela que "tinha estabelecido definitivamente um objetivo - permanecer aqui e concorrer breve a uma cadeira na Escola de Enge'nharia". Finalmente, em 25 de junho, diz o engenheiro a João Luís: "vejo muito comprometido o meu concurso; estou vendo que não me inscreverei" (Cunha, 1896). De fato, Euclides não se inscreveu para o concurso, que não teve candidatos.

No âmbito da Politécnica a vaga de professor da cadeira de mineralogia e geologia foi preenchida com a nomeação por proposta da Congregação do $l^{\circ}$ tenente reformado da Armada Nacional, Antonio de Barros Barreto (Relatório da Politécnica, 1896:4), que toma posse e entra em exercício a 2 de outubro de 1896, como professor substituto, vindo posteriormente a ser lente catedrático da cadeira.

Paula Souza, falando aos colegas na reunião da Congregação do dia 22 de agosto de 1896, afirmou não conhecer Antonio de Barros Barreto, estando apenas informado de que se tratava de “(...) uma pessoa que se tem ocupado do ensino de diversas matérias, especialmente de ciências matemáticas e naturais 
(...)". Anotou ainda o secretario da Congregação que "não se referindo as informações obtidas a matérias da cadeira que se quer preencher, o dr. diretor fica encarregado de obter outras mais detalhadas que apresentará na próxima reunião" (Atas da Congregação, 1896).

O diretor da Politécnica consultou o então seu amigo Orville Derby sobre a competência de Antonio Barreto e deu conta à Congregação de que "(...) as informações obtidas são as melhores possíveis não tanto em relação a estudos especiais de mineralogia, mas quanto a sua capacidade, aptidão, e dedicação ao estudo, sendo de parecer o Dr. Derby que se lhe pode confiar o ensino". Nesta mesma reunião o lente Garcia Redondo lembrou aos colegas que era "(...) especialmente habilitado o candidato por seus conhecimentos químicos e físicos" (Atas da Congregação, 1896).

A expectativa de que o professor da cadeira de Mineralogia e Geologia fosse um especialista (Francisco Oliveira) não se concretizou. Antonio de Barros Barreto, assim como Euclides da Cunha, não era um especialista no assunto, e, como este, era um engenheiro reformado da carreira militar.

Entre 1897 e 1902, Euclides da Cunha realiza e publica Os sertõese, apesar do seu completo envolvimento com a construção da ponte de São José do Rio Pardo e o livro que mudaria a sua vida, encontra tempo para tratar do assunto Politécnica.

Primeiro em carta a Alberto Sarmento, datada de 22 de fevereiro de 1901, informa que “(...) em São Paulo alguns amigos, lentes da Politécnica, manifestaram-me o desejo de que eu entrasse para ela. É uma resolução vaga ainda, adstrita a muitas alternativas" (Cunha, 1966:613). Depois, ao escrever a Francisco Escobar - 14 de maio de 1902 - quando afirma ser “(...) possível que tome, afinal, a resolução de ir para a Politécnica, onde há bons companheiros e poderei encontrar os elementos que faltam nesta convivência estúpida com as dezenas de empreiteiros que me rodeiam" (Cunha, 1966:617).

Entre os "amigos, lentes da Politécnica", por certo estava Manuel Garcia Redondo, um dos fundadores da Academia Brasileira de Letras e responsável pela intermediação que levaria Euclides da Cunha até a Casa Laemmert, onde foi publicado o seu livro (Gikovate, 1982:35).

Respondendo à consulta de Euclides sobre a Escola, Garcia Redondo escreveu-lhe, em 26 de agosto de 1903, para dizer da sua intenção de “(...) adiar a indicação para o próximo ano vindouro". (Redondo, 1903). Realmente, em 1904 foram intensificadas as negociações para viabilizar o ingresso de Euclides da Cunha na Escola Politécnica de São Paulo.

Um dos articuladores foi Henrique Coelho, funcionário da Secretaria do 
Interior do Estado de São Paulo e ex-companheiro de colégio de Euclides. É dele a carta de 11 de junho de 1904 que transcrevo a seguir: "Euclides, / Só ontem, por estar o Cardoso atarefadíssimo com os serviços da Secretaria, e por ter o Ramos a lida dos exames na Escola, é que se realizou a conferência, para decidir-se o negócio. / Da conversa o que ambos apuraram é que faz-se preciso cabalar o Redondo, ao qual compete fazer a proposta. / Para isso, convém que dês um pulo até cá, a fim de preparar o terreno. / Se deres um pouco de tempo ao tempo, tudo se arranjará. / Compreendo a tua impaciência, mas não custa, por mais alguns dias, aguardar a solução. / Continuo a garantir-te, por parte do Cardoso, a melhor boa vontade. / E quanto a mim não cometerei a monstruosidade de deixar de fazer o que puder pela justíssima pretensão do escritor de $O s$ sertões. / Abraça-te o / Henrique Coelho"

Como se percebe, além de Garcia Redondo e Henrique Coelho, também estavam envolvidos nas negociações o então secretário da Justiça do Estado de São Paulo, Cardoso de Almeida e o vice-diretor da Politécnica, Ramos de Azevedo.

O envolvimento de Henrique Coelho era de tal ordem que a 28 de junho de 1904 um certo José a ele se dirigiu dando conta de conversa mantida com Ataliba do Vale, lente da Escola. Ataliba afirmara que a candidatura de Euclides da Cunha ia muito bem, que parecia coisa certa, “(...) na última Congregação o Redondo falou a respeito, que todos consideraram excelente aquisição (...)" (José, 1904). Adiantava ainda o catedrático da Politécnica que a postulação seria levada ao diretor Antonio Francisco de Paula Souza.

Se Garcia Redondo tratou do assunto na reunião da Congregação realizada no dia 6 de junho, o fez oficiosamente, nada constando a respeito na ata da mesma. Esta reunião tratou, dentre outras coisas, do preenchimento de vagas para professor substituto, ficando o tema de ser retomado após as férias, como bem informara Ataliba do Vale.

O material consultado não registra qual o teor da possível conversa entre Garcia Redondo e Paula Souza. No entanto, o ânimo e a reação de Euclides, gravados em correspondências que tratam da questão, deixam claro que se a conversa existiu os seus resultados não foram favoráveis aos seus planos.

No dia 23 de julho de 1904, escrevendo a Plínio Barreto, colega jornalista de $O$ Estado de S. Paulo, Euclides da Cunha utiliza um apelido, "o Escangalhador", para referir-se a Garcia Redondo, afirmando que "(...) já lhe sabia da capoeiragem a que não devemos dar nenhuma importância” (Barreto, 1952:5)

Mais explícita é a correspondência do autor de Os sertões a Coelho Neto, de 7 de agosto do mesmo ano: "quanto à Politécnica: ia tudo admiravelmente eu queria, o governo queria muito, a Congregação queria muitíssimo a minha 
nomeação, porém, à última hora razões muito sérias, e muito honestas, obrigaram-me a escrever ao Sr. Garcia Redondo uma carta que era, afinal, o rompimento das nossas relações (...) renunciei desabridamente à pretensão. Mas muitos não me entendem neste ponto, de sorte que talvez ainda seja surpreendido com a nomeação" (Cunha, 1966:648).

Mesmo com a nomeação para a Comissão de Reconhecimento do Alto Purus já assegurada, o escritor reafirmou em carta a seu pai, de 8 de agosto, a intenção de conseguir "(...) do governo do estado de São Paulo, onde conto com as melhores simpatias a nomeação para a Politécnica - para exercer este cargo definitivo, na volta da minha comissão que será naturalmente provisória" (Cunha, 1904).

Empenhado em conseguir a nomeação do amigo e vendo se aproximar a data da Reunião da Congregação que trataria do assunto, Henrique Coelho lhe escreveu no dia 13 de agosto de 1904, alertando que "(...) no dia 15 deve se resolver o negócio da Politécnica, será bom que você me mande um telegrama amanhã, de modo que amanhã mesmo eu o transmita ao Ramos [de Azevedo], declarando que não desistes da candidatura ao lugar de lente" (Coelho, 1904).

Nessa carta, Henrique Coelho indicou também como conciliar a pretendida nomeação para a Escola com a já confirmada nomeação para a comissão dos limites: "desde que você tem prazo para tomar posse, desde que esse prazo, que se não me engano é de dois meses, pode ser prorrogado, e desde que há ainda o recurso de pedir licença para tratar de interesses e, portanto, sem vencimentos, acho que você não deve renunciar à colocação aqui, que além do mais é definitiva" (Coelho, 1904).

Por conta do pouco tempo para encaminhar a questão, Henrique Coelho pediu para ser logo avisado da decisão do escritor, como forma de estarem prevenidos com qualquer desculpa de última hora.

Não tendo conhecimento do telegrama-resposta, entendo que inferências podem ser retiradas das atas da Congregação que trataram das nomeações da Politécnica e de outras correspondências de Euclides da Cunha.

Em 16 e 27 de agosto de 1994 a Congregação esteve reunida para tratar das vagas para professores substitutos, ficando resolvido que as mesmas seriam preenchidas por indicação da própria Congregação, em processo que previa a realização de duas reuniões, uma para a indicação dos candidatos e a outra para a votação dos nomes indicados (Atas da Congregação, 1904).

No dia 9 de setembro, data em que se realizou a reunião para indicação dos candidatos, Euclides da Cunha, ciente do novo insucesso de sua antiga pretensão, conforme comunicou a Henrique Coelho em carta de 9 de setembro, 
abençoando a hora em que desejou “(...) ser um simples lente substituto da Escola Politécnica de São Paulo! (...) mas o fato é que foi - graças aos mais justos motivos - removido para o futuro, um futuro indeterminado, a realização do velho ideal. E só por esta circunstância já não creio nela. Mudam vertiginosamente os tempos e os homens" (Cunha, 1966:653).

Vendo inviabilizados os seus planos, buscou Euclides ressaltar ao amigo o que de positivo restara do episódio, o que o levou a encontrar espaço para se autoparabenizar e declarar: "ganhei a partida". Ainda que não explicite contra quem estava disputando a "partida", isto evidencia a existência de posição contrária ao seu ingresso na Escola Politécnica de São Paulo.

Nessa carta, Euclides da Cunha ainda se refere às “(...) palavras animadoras e cativantes de Ramos de Azevedo [que] foram certamente sinceras [pois] homens daquela têmpera não disfarçam o sentir, nem precisam disfarçá-lo" (Cunha, 1966:653).

Ramos de Azevedo estava presente à primeira das reuniões extraordinárias da Congregação, a que indicou os candidatos a professor. A reunião apresentou o seguinte resultado após o recolhimento de 20 cédulas para cada uma das seções onde existiam vagas: " $2^{\mathrm{a}}$ seção - (...) nove cédulas contendo o nome do Dr. Afonso Taunay, cinco contendo o nome do Dr. Regino Aragão; três com o nome do Dr. Custódio Braga; uma com o nome do Dr. Euclides Cunha (sic) e duas em. branco. / $4^{a}$ seção - (...) quinze cédulas contendo o nome do Dr. Jorge Krug; uma com o nome do Dr. Euclides Cunha e quatro em branco. / $6^{\mathrm{a}}$ seção quinze contendo o nome do Dr. Clodomiro Pereira da Silva; uma com o nome do Dr. Euclides Cunha e quatro em branco. / $7^{\text {a }}$ seção - (...) 17 contendo o nome do Dr. José Maria Borges; uma com o nome do Dr. Euclides Cunha e duas em branco" (Atas da Congregaşão, 1904).

Na reunião de indicação de candidatos os nomes foram apresentados sem discussões e todos, conforme previa o regulamento, foram levados à nova reunião da Congregação para serem debatidos. Essa reunião aconteceu uma semana após, e contou com a presença de 19 lentes.

A $2^{\text {a }}$ seção, com quatro nomes indicados, foi a que teve o maior número de intervençõès. Seis lentes (Rondeli, Magalhães Gomes, Rabelo, Fajardo, Teles e Shalders) utilizaram a palavra para a defesa dos nomes dos candidatos Afonso Taunay, Regino de Aragão e Custódio Braga, que obtiveram respectivamente onze, dois e cinco votos, registrando-se ainda um voto em branco. $O$ nome de Euclides da Cunha não foi defendido por qualquer dos presentes e não obteve voto.

Quando da discussão sobre os candidatos à $4^{\mathrm{a}}$ seção, o vice-diretor, Ramos de Azevedo, utilizou a palavra para defender o nome de Jorge Krug. O resultado apontou: Jorge Krug, dezoito votos; Euclides da Cunha 1 voto. 
Um dos candidatos à $6^{\mathrm{a}}$ seção, Clodomiro P. da Silva, foi defendido pelo lente S. Thiago, obtendo 17 votos. Duas cédula estavam em branco, não constando voto para Euclides da Cunha.

A última votação foi feita para a $7^{\mathrm{a}}$ seção. Ramos de Azevedo e o diretor Paula Souza elogiaram o candidato José Maria Braga, que recebeu 18 votos. Como nas demais votações, não foram registradas palavras para o nome de Euclides da Cunha, que obteve um voto.

Quando o nome de Euclides da Cunha foi apresentado formalmente à Congregação, já não se tratava do jovem engenheiro de 1892, mas do famoso escritor, a quem Os sertões abrira as portas do Instituto Histórico e Geográfico Brasileiro, da Academia Brasileira de Letras e até mesmo garantira um cargo em comissão no Itamaraty. Além disso, o escritor partilhava da amizade de lentes da Politécnica e de setores do governo paulista, que articulavam o seu acesso à Escola.

Como entender então o que se passou nas duas reuniões da Congregação citadas anteriormente?

No último registro que encontrei sobre o assunto Politécnica, Euclides da Cunha intenta o que pode ser considerada uma versão oficial para o desenlace desfavorável às suas aspirações.

Em carta a Plínio Barreto, sem data, mas claramente do ano de 1904, às vésperas do embarque para a Amazônia, Euclides da Cunha explica que “(...) seria nomeado agora para a Politécnica. Imagina que o substituto do Redondo é obrigado a ensinar veterinária... Lá está no regulamento. Eu li. Singularíssimo e epigramático. Recusei e foi uma solução belíssima" (Barrețo, 1952:5)

Muito embora esta versão esteja compatível com o fato de que Euclides não andava às boas com Garcia Redondo e com a constatação de que peterinária não era um tema pelo qual ele tenha em algum momento demonstrado afinidade - a própria zoologia é o ramo da história natural menos abordado em $O s$ sertões-, acredito que outro entendimento pode ser apresentado para a questão.

Tanto a cautela demonstrada por Garcia Redondo na escolha do momento mais adequado para apresentar o nome de Euclides da Cunha, quanto as preocupações de Henrique Coelho com as desculpas de última hora, sem esquecer o ânimo do candidato nos momentos que antecederam à decisão, levam-me a pensar na existência de um obstáculo de grande porte dentro da Escola Politécnica.

Este obstáculo chamava-se Antonio Francisco de Paula Souza, diretor da Escola desde a sua fundação em 1893 até o ano de 1917, quando faleceu. Apesar 
de caber à Congregação a indicação dos candidatos às vagas de professores, o fato é que o diretor Paula Souza era “(...) reconhecidamente um homem de forte personalidade (...) [e] conseguia enfeixar em suas mãos uma soma razoável de poder" (Nadai, 1981:98-99).

Não se pode perder de vista que a crítica contundente feita por Euclides da Cunha em 1892 não se furtava a nominar o autor do "desastroso projeto", no qual o jovem engenheiro encontrara tantos "defeitos e incorreções" que nem mesmo o próprio autor "ousaria arrostar as conseqüências de defendê-lo".

Quando Euclides da Cunha declarou-se vencedor numa polêmica que não aflorou, em 1892, mal podia imaginar que, na verdade, estava apenas iniciando uma contenda que prosseguiria até o ano de 1904, com algumas etapas diferenciadas.

O Euclides da Cunha que em 1893 alimentou esperanças de integrar os quadros da Escola Politécnica de São Paulo era um jovem engenheiro que expressava destemida e desabridamente as suas idéias sobre política e ciências através de artigos publicados em jornais e, acima de tudo, alguém que buscava uma solução civil e estável para livrá-lo de uma vez da farda de oficial do exército que já o incomodava.

A "censurável preterição" a que se referiu Reinaldo Porchat ao comentar a não-inclusão do nome de Euclides da Cunha no primeiro quadro de professores

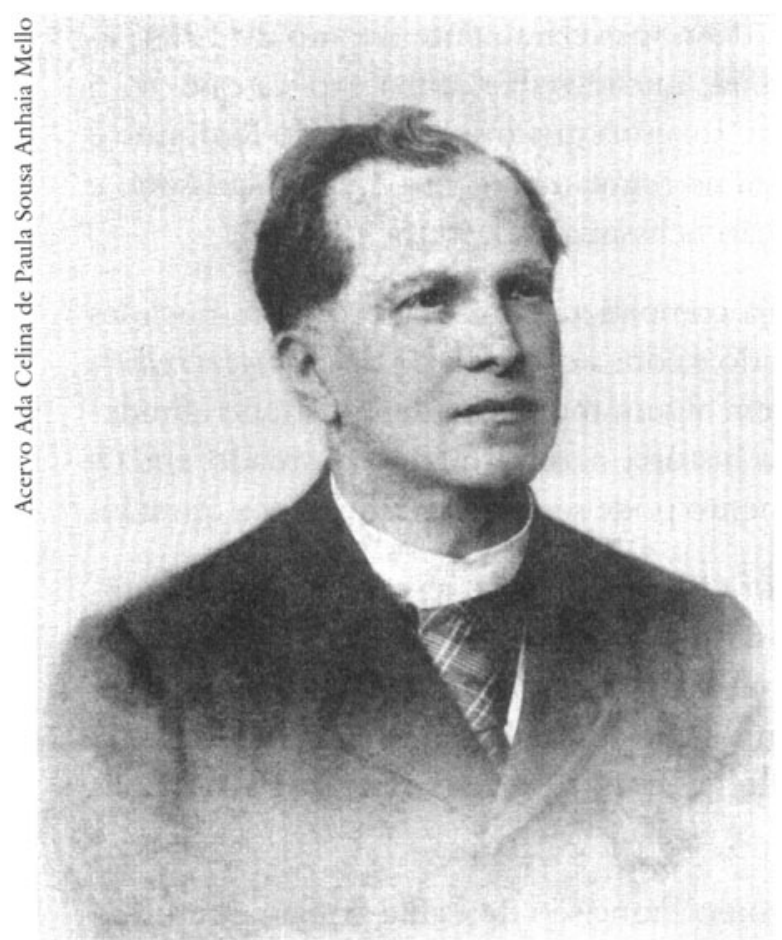

Paula Souza, retrato de 1865 da Politécnica, nomeados pelo governo do estado de São Paulo, foi uma das etapas da contenda.

Entre 1895 e 1896, a perspectiva de um concurso, para lente da Escola Politécnica da São Paulo, levou Euclides da Cunha a absorver-se pelos estudos de mineralogia, provavelmente julgando ser este o único caminho de acesso ao seu sonho.

$\mathrm{O}$ concurso sequer era o caminho preferido pela Congregação da Politécnica, que, habilmente, articulou pela sua não-realização e assumiu para si o poder de escolher os professores da Escola, o que significava, de fato, exercer o poder de vetar acessos. 
As alegadas restrições à seita positivista de Euclides, a explícita preferência de Paula Souza pelo nome de Francisco Oliveira, a posterior nomeação de Antonio de Barros Barreto para a cadeira de Mineralogia e Geologia e as alusões aos artigos do jornal $O$ Estado de $S$. Paulo também podem ser entendidas como um novo momento dos episódios de 1892.

Em 1904, para o já consagrado escritor de Os sertões, a Escola Politécnica de São Paulo continuava a representar a possibilidade de acesso a um cargo definitivo que ainda oferecia a oportunidade de encontrar os elementos que faltavam na convivência, que o próprio Euclides adjetivava de estúpida, com as dezenas de empreiteiros que rodeavam as suas atividades de engenheiro civil.

Buscava Euclides da Cunha um lugar entre os que imaginava fossem os seus pares, tornando menos áspera a sua engenharia e permitindo a continuidade daquela que, sem dúvidas, era a sua ocupação preferida: a atividade intelectual.

Os cuidados demonstrados, em 1904, pelos articuladores da candidatura de Euclides tinham como objetivo vencer a principal resistência interna existente na Congregação, representada pelo diretor da Escola.

Às vésperas da reunião do Colegiado, fazia-se necessário submeter à consideração de Paula Souza o nome de Euclides da Cunha. A partir de então a candidatura naufraga.

A apresentação do escritor de Os sertões para todas as seções em discussão ( $l^{a}$ reunião da Congregação), e o voto obtido para duas seções ( $2^{a}$ reunião da Congregação), provavelmente de autoria de um mesmo lente, além de registrar uma posição contra as restrições, viabilizava que o nome de Euclides fosse levado ao governo, a quem caberia decidir, dentre os nomes indicados, quais os que seriam nomeados, independentemente do número de votos.

Esse fato permitiu a Euclides manter acesa a possibilidade da nomeação por mais algum tempo e, sem se referir a à inegável derrota diante do adversário antigo,

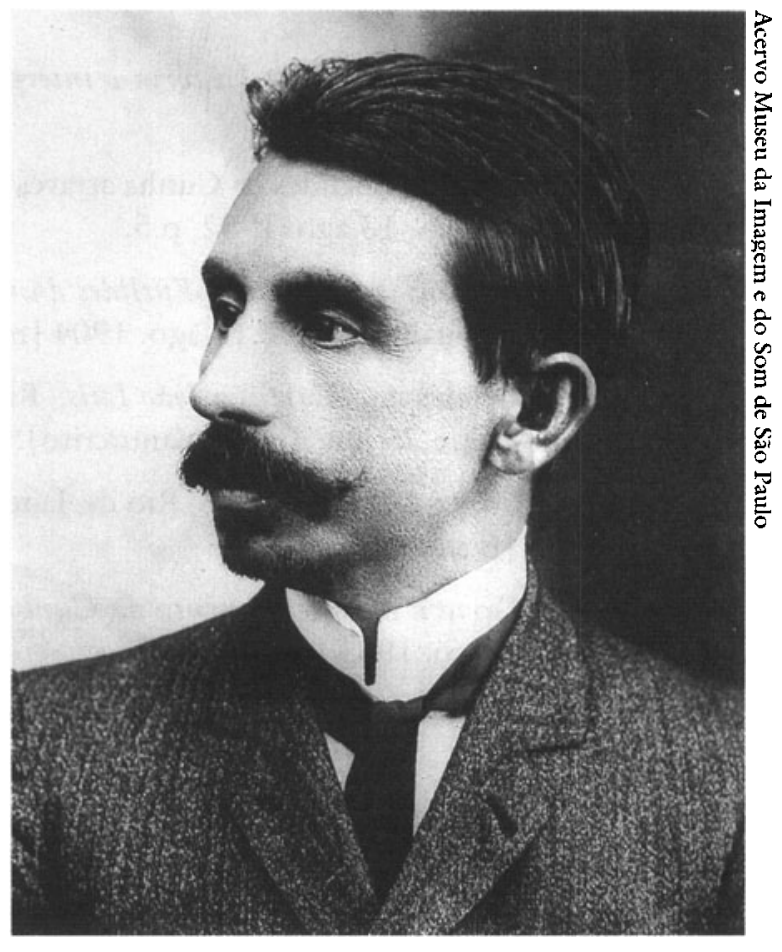

Euclides da Cunha, retrato de 1906 
até encontrar uma "solução belíssima", a "recusa", que atenderia plenamente os" lados envolvidos. Após tal desenlace, não voltaria Euclides da Cunha a manifestar-se a respeito da Politécnica.

A consulta aos documentos da Escola mostra que era bastante comum a Congregação manifestar condolências e fazer-se representar em funerais de pessoas de variados níveis de notoriedade. No entanto, sequer a forma trágica da morte do famoso escritor, que comoveu o país em 1909, motivou uma simples menção ao autor de Os sertões nas atas da Escola, cujas portas nunca se abriram para Euclides da Cunha.

Nota

1 Não consta no livro de registro das nomeações, existente no Arquivo da Escola Politécnica, ou nos trabalhos consultados de/ou sobre Teodoro Sampaio, nenhuma informação sobre a sua nomeação para a Escola Politécnica de São Paulo. Todos os outros citados foram efetivamente nomeados. Um deles, Luiz Gonzaga de Campos, não aceitou a nomeação e não foi empossado (Relatório da Politécnica, 1894).

\section{Referências bibliográficas}

ANDRADE, Olímpio de S. História e interpretação de Os sertões. São Paulo, EDART. 1960. $329 \mathrm{p}$.

BARRETO, Plínio. Euclides da Cunha através de algumas cartas íntimas. $O$ Estado de $S$. Paulo, São Paulo, 13 ago. 1952, p.5.

COELHO, Henrique. Cartas a Euclides da Cunha. Rio de Janeiro, Arquivo da Biblioteca Nacional. 11 jun. e 13 ago. 1904 [manuscrito].

CUNHA, Euclides da. Cartas a João Luís. Rio de Janeiro, Arquivo da Biblioteca Nacional, 23 abr. e 25 jun. 1896 [manuscrito].

- Carta a Dr. Brandão. Rio de Janeiro, Arquivo da Biblioteca Nacional, 28 abr. 1896 [manuscrito].

Carta a Manuel Pimenta da Cunba. Rio de Janeiro, Arquivo da Biblioteca Nacional, 8 ago. 1904 [manuscrito].

1959.

Dia a dia. Repista do Lipro. Rio de Janeiro, ano 4, n. 15, p. 109-112, set.

Epistolário. In: COUTINHO, A. (org.) Euclides da Cunba-Obra completa, v. 2. Rio de Janeiro, José Aguilar, 1966, p. 591-713.

ESCOLA POLITECNICA DE SÃO PAULO. Livros de atas da Congregafão. .São Paulo, Secretaria da Congregação da Escola Politécnica, 1896-1909 [manuscrito]. 
- Relatório (1896). São Paulo, Tipografia do Diário Oficial, 1895.

Relatório (1896). São Paulo, Tipografia do Diário Oficial, 1897.

1900. Anuário (1900). São Paulo, Tipografia do Diário Oficial, 1900, ano I, v. 1,

FIGUEIRÔA, Silvia F. M. Modernos bandeirantes. São Paulo. 1987. 162 p. Dissertação (mestrado), Faculdade de Filosofia, Letras e Ciências Humanas, Universidade de São Paulo.

- A ciência na busca do Eldorado: a institucionalização das ciências geológicas no Brasil, 1808-1907. São Paulo. 1992. 172p. Tese (doutorado), Faculdade de Filosofia, Letras e Ciências Humanas. Universidade de São Paulo.

GICOVATE, Moisés. A vida numa curva de linhas retas. Os sertões nos anos 80 . São Paulo, Diário Oficial, 1982, p. 31-36.

JOSÉ. Carta a Henrique Coelho. Rio de Janeiro, Arquivo da Biblioteca Nacional. 28 jun. 1904 [manuscrito].

NADAI, Elza. Ideologia do progresso e ensino superior (São Paulo 1891-1934). São Paulo, 1981. Tese (doutoramento). Faculdade de Filosofia, Letras e Ciências Humanas. Universidade de São Paulo.

PORCHAT, Reynaldo. Carta a Euclides da Cunha. Rio de Janeiro, Arquivo da Biblioteca Nacional, 26 nov. 1893 [manuscrito].

REDONDO, Garcia. Carta a Euclides da Cunba. Rio de Janeiro, Arquivo da Biblioteca Nacional, 26 ago. 1903 [manuscrito].

SAMPAIO, Teodoro. Carta a Euclides da Cunba. Rio de Janeiro, Arquivo da Biblioteca Nacional, 19 ago. 1893 [manuscrito].

SANTOS, Maria C.L. dos. Escola Politécnica (1894-1984). São Paulo, Reitoria USP/ Escola Politécnica, Fund. Des. Tec. Eng., 1985.

VARGAS, Milton. A história da Poli, ou a idéia frustrada do ensino prático. In: Folha de S. Paulo, São Paulo, 15 ago. 1993. Caderno Especial Poli, p. A.2.

José Carlos Barreto de Santana é professor do Departamento de Ciências Exatas da Universidade Estadual de Feira de Santana (UEFS-BA) e doutorando em História Social pela Universidade de São Paulo. 